\title{
A method for quantifying differentiation between populations at multi-allelic loci and its implications for investigating identity and paternity
}

David J. Balding $\cdot$ Richard A. Nichols

Published online: 9 August 2007

(C) Springer Science+Business Media B.V. 2007

Erratum to: Genetica 96: 3-12 (1995)

DOI 10.1007/BF01441146

This erratum is being published as a result of incorrect parameters of Table 2.

Table 2 should be now read as:
Table 2 Single-locus likelihood ratios for paternity when the mother's genotype is $A A$. Blank entries indicate that the alleged father is excluded

\begin{tabular}{lll}
\hline Alleged Father & \multicolumn{1}{l}{ Child } \\
\cline { 2 - 3 } & $\mathrm{AA}$ & $\mathrm{AB}$ \\
\hline$A A$ & $\frac{4 F+(1-F) p_{A}}{1+3 F}$ & \\
$A B$ & $2\left(\frac{3 F+(1-F) p_{A}}{1+3 F}\right)$ & $\left(\frac{2 F+(1-F) p_{B}}{1+3 F}\right)$ \\
$B B$ & & $\frac{2 F+(1-F) p_{B}}{1+3 F}$ \\
$B C$ & & $2\left(\frac{F+(1-F) p_{B}}{1+3 F}\right)$
\end{tabular}

The online version of the original article can be found under doi: 10.1007/BF01441146.

D. J. Balding $(\square) \cdot$ R. A. Nichols

School of Mathematical Sciences and School of Biological

Sciences, Queen Mary \& Westfield College, University

of London, Mile End Road, London E1 4NS, UK

e-mail: d.balding@imperial.ac.uk 